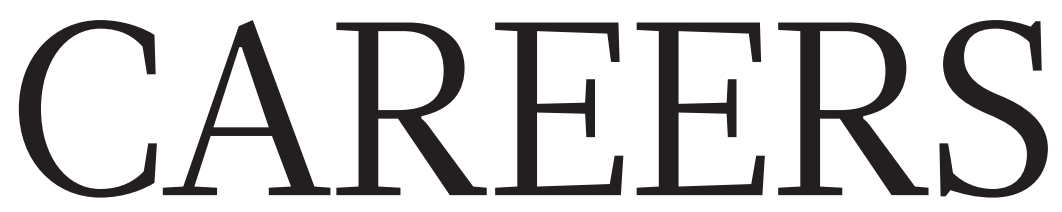

PARTICIPANTS WANTED Take our Nature PhDstudent survey go.nature.com/2wt3cpm

MENTAL HEALTH Advice and support at go.nature.com/wellbeing
SOCIAL Follow us on Twitter at twitter. com/NatureCareers

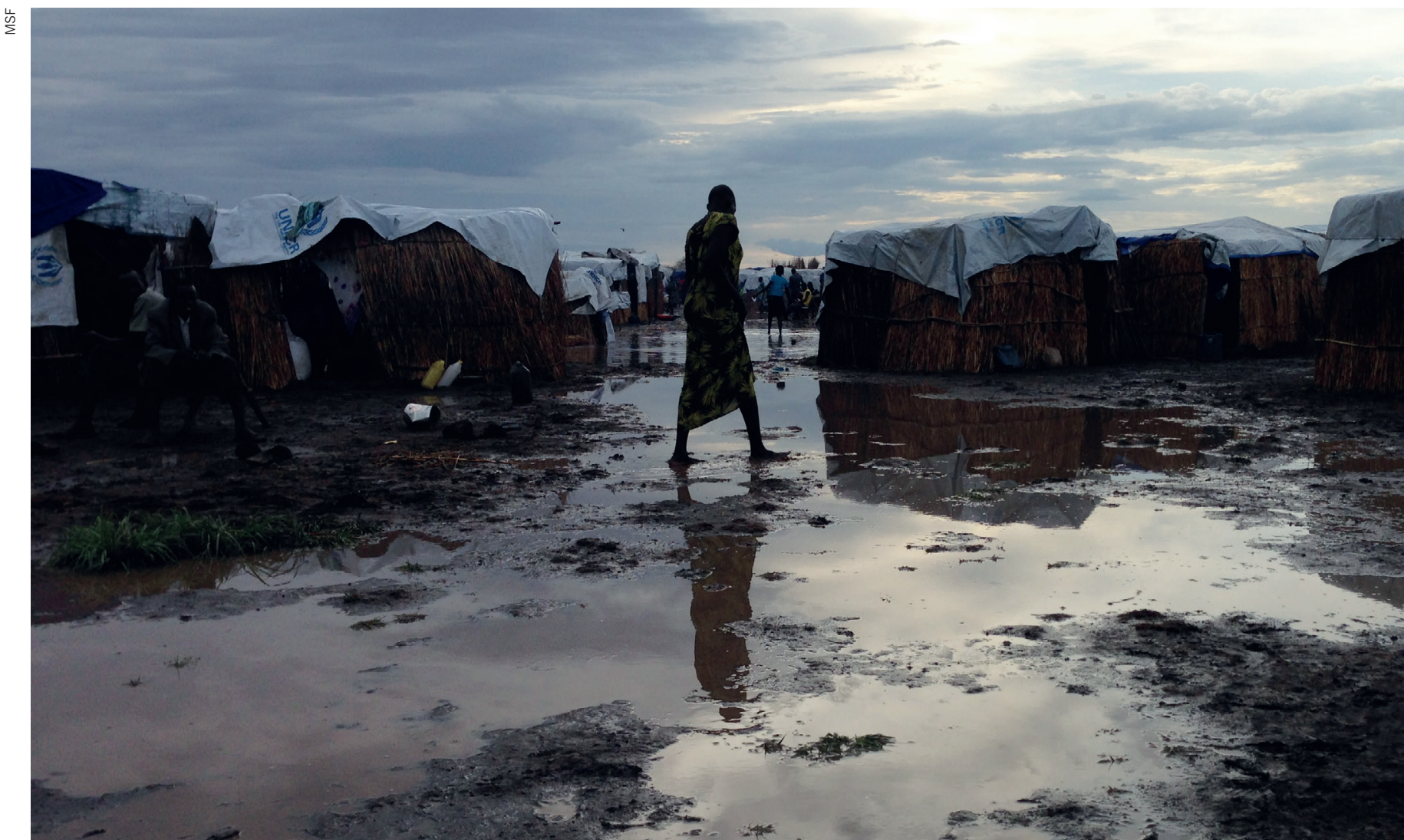

Large numbers of people from South Sudan are seeking refuge in camps in the Gambella region of Ethiopia.

\title{
DISASTER RESEARCH
}

Science in a crisis

Gathering data and creating models in the midst of a humanitarian crisis can be emotionally harrowing, but many find rewards in the chance to make a difference.

\section{BY JACK LEEMING}

A lthough most scientists face pressures and stress in their working lives, those whose work takes place in an evolving humanitarian emergency must cope with even greater responsibility and pressure. Nature speaks to three researchers about how their work has had a direct effect on saving people's lives, and how science is done during a crisis. Their experiences and the scope of their research are diverse, but the researchers are united by the shared goal of using science to make an impact on the world and ultimately save lives.
ANNICK LENGLET

\section{Refugee crisis} tracker

Epidemiology adviser at Médecins Sans Frontières in Amsterdam.

South Sudan seceded from Sudan in 2011 after more than 50 years of unrest and civil war.

By 2013, the ongoing civil conflict in the newly created country had escalated. South Sudanese refugees crossed the Baro and Akobo rivers to the Gambella region of neighbouring Ethiopia, arriving at camps that were chaotic and hastily built, with limited food supplies and poor hygiene and sanitation.

Annick Lenglet, an epidemiologist with the aid organization Médecins Sans Frontières (MSF, also known as Doctors Without Borders), began working at the camps that year. When she arrived, there was no governance, health care or administration - the refugees, exhausted, had just stopped walking. Lenglet and other first responders built a health-care plan. "I was one of the first people deployed as part of the response of MSF, and there's nothing there," she says. Lenglet had to travel 
- from Gambella town to the camps for an hour in the back of a truck with ten other MSF staff. “There's no system in place. You're going to the camps every single day, trying to talk to people and figure out how to help."

Lenglet's job was not to assist the medical professionals, but to collect data about the refugees so that her colleagues could better respond to the crisis. Public-health professionals know that when vulnerable people travel long distances - without much food, in large numbers, and in intense daytime heat and bitter night-time cold - disease travels with them.

Lenglet tried to measure the factors affecting the refugees. "Those are the questions that I set out to answer as an epidemiologist. How many people are there? How many people are dying? That is the first indicator of how badly off they are. Then you want to look at the prevalence of malnutrition: do people have enough food? Are children presenting with severe malnutrition?" In cases like this, Lenglet says, MSF will consider a variety of different facilities. If children are too weak to eat, for example, the organization might set up an inpatient centre equipped with gastric tubes and high-calorie milk. In most cases, charitable organizations such as MSF provide food such as high-calorie biscuits to outpatients.

The Administration for Refugees and Returnees Affairs, an agency based in Addis Ababa, used the information that Lenglet collected to coordinate a humanitarian response for those living in the camps - providing essentials such as a water supply and shelter against Gambella's harsh climate, where temperatures regularly rise above $30^{\circ} \mathrm{C}$.

To ensure MSF and the organizations it works with can respond rapidly, Lenglet says, scientific robustness takes a secondary role to gathering information. Because data collection takes place in the chaos of a refugee camp, the research tends to be more qualitative and piecemeal than is standard epidemiological work, and it is based on interviews and intuition rather than on hard numerical data. And any existing data tend to be incomplete.

"It does cause an inherent level of stress within anybody who claims to be scientifically trained," she says. "In the first two weeks you're expected to have this stockpile of information which can lead to implementing health centres or running mobile clinics or implementing a vaccination campaign."

The work can be exhausting. "People are much more vulnerable to really horrific diseases and death because they haven't had access to care," she says. "You wake up at 5.30 a.m., come back at 5 or 6 when it gets dark and spend the next three hours doing data entry or calculating so you have some data output for that day."

"You're feeling tired; you're feeling hot. You're going through everything from deep depression to exhilaration in a single day. The immediacy of what needs to happen becomes clear, and your empathetic side kicks in because you talk to people and become a part of what's happening."

Lenglet's work brings her into close contact with others' experiences. "You are confronted with really awful and painful personal stories of patients and their families. You bear witness to some of the more horrific things that humans are able to do to each other," she says. "That can be hard. It never really leaves you."

Her experiences have left a lasting mark. "I will never be able to fully grasp the pain, fear, or suffering of what some of the people go through in the places where MSF works," she says.

Lenglet advises scientists who work in crisis situations to take an occasional step back when faced with stressful work, both in the office and in the field, however difficult doing so might be. "One thing I tell field epidemiologists I mentor is to take at least a full day off every week, and don't do anything that's to do with work," she says. "Even if you don't think it, you need that time to recuperate."

One basic piece of advice with obvious benefits is to get enough sleep. "I know the more tired I get, the worse the stress will become," she says. Time away can help. "Just to take even five minutes to do something different" is important, she says.

The refugee camps remain in Gambella, and, by August 2018, the number of South Sudanese there had grown to more than 400,000 - around the same as the local Ethiopian population. Lenglet has since returned to Amsterdam where she still works as an epidemiologist at MSF.

Overall, Lenglet says, the job is worth the stress - she draws satisfaction from

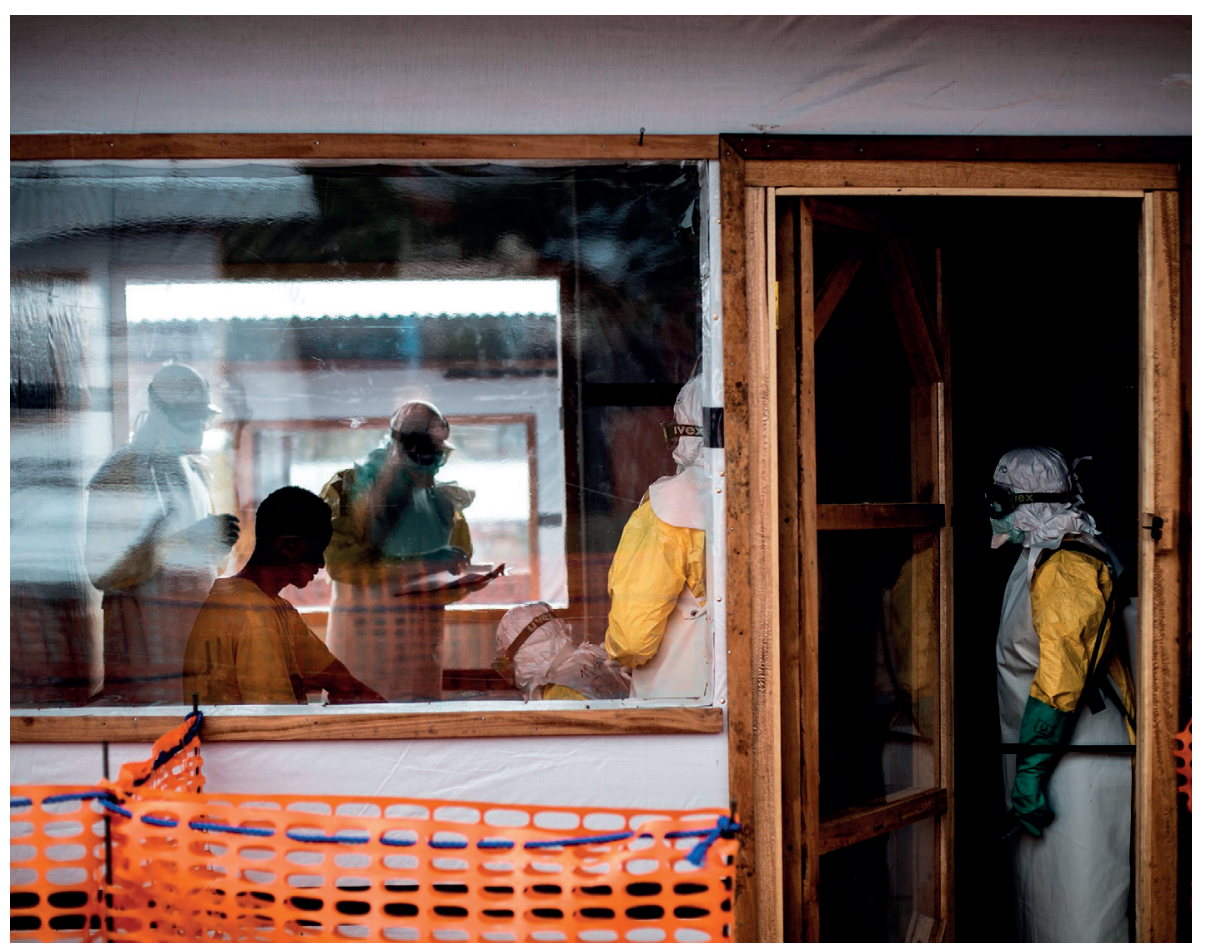

Health workers run clinics in the Democratic Republic of the Congo for people with Ebola. the impact she has on improving care for an extremely vulnerable group of people. "Even if I'm not directly saving one individual's life, I feel extremely privileged and part of something," she says.

\section{SEBASTIIAN FUNK Ebola predictor}

\section{Statistical modeller at the London School of Hygiene and Tropical Medicine.}

Sebastian Funk helped to develop an online data resource to help distribute scarce medical resources during the 2014-16 Ebola epidemic in West Africa.

The disease tore across Guinea, Liberia and Sierra Leone with a $70 \%$ mortality rate, aided by the relative free movement of people across borders, local distrust in government publichealth services and by its presence in urbanizing and densely populated areas where it spread through close contact. In 2016, the World Health Organization (WHO) reported 11,310 deaths from Ebola in the three countries during the epidemic.

Funk and his colleagues at the London School of Hygiene and Tropical Medicine's Centre for the Mathematical Modelling of Infectious Diseases (CMMID) used data on Ebola diagnoses and infection rates to build statistical predictions of how the disease was likely to proceed. They constructed their projections with information from public-health workers in West Africa and existing disease 
models. The team published those predictions openly online and updated them weekly.

Public-health planners who were managing the movement of staff, medicine, food, water and hospital beds used the online data to make better decisions on where to direct resources to prevent the further spread of disease and treat patients. "It's about making decisions and allocating resources for [problems like] bed capacity," Funk says. If the team predicts that Ebola is likely to spread into a new province, for example, MSF or the WHO might choose to send doctors, hospital beds and medical supplies to that region.

Funk and colleagues launched the website in December 2014 and kept it updated until October 2015. In the weeks before launching the site, every Thursday, Funk and his team e-mailed reports of their predictions to decision-makers at humanitarian organizations working in the region, including the United Nations, the WHO, Save the Children and the Bill and Melinda Gates Foundation based in Seattle, Washington.

The work was not easy. The scientists had to produce results each week with updated mathematical models that better fit the observed disease outbreaks. "Some of my colleagues would stay in the lab because it was just easier to spend the night there and get back to the work in the morning," he says.

The researchers' efforts to predict the spread of viruses in real time are often unfunded and have to be completed over weekends or in spare evenings alongside ongoing funded academic responsibilities. But, Funk says, "there's a reward for that an ethical reward for doing something that's practical and useful".

Funk says that those academic responsibilities, such as applying for grants and producing papers, bring their own stress that often eclipses the pressure he experiences from delivering on public-health initiatives. Either way, he's happy to be taking part.

"On one hand there's this pressure and stress of getting work done at short notice," he says. "But in the line of work that we're in, we're all here because we want to do some good and do something that ultimately saves lives."

Funk and the CMMID team have used similar methods to model a 2017 diphtheria outbreak among Rohingya refugees in Bangladesh, in collaboration with MSF. The team is also involved in ongoing efforts to combat the ninth Ebola outbreak in the Democratic Republic of the Congo. Some researchers are carrying out data-analysis work in the country; others are modelling the roll-out of a second Ebola vaccine.

Since his involvement in the response to the West African epidemic, Funk has received a $£ 1$.6-million (US\$2-million) fellowship from the London-based biomedical charity Wellcome to support his work in real-time forecasting of diseases. The fellowship started last September and will end in 2023.

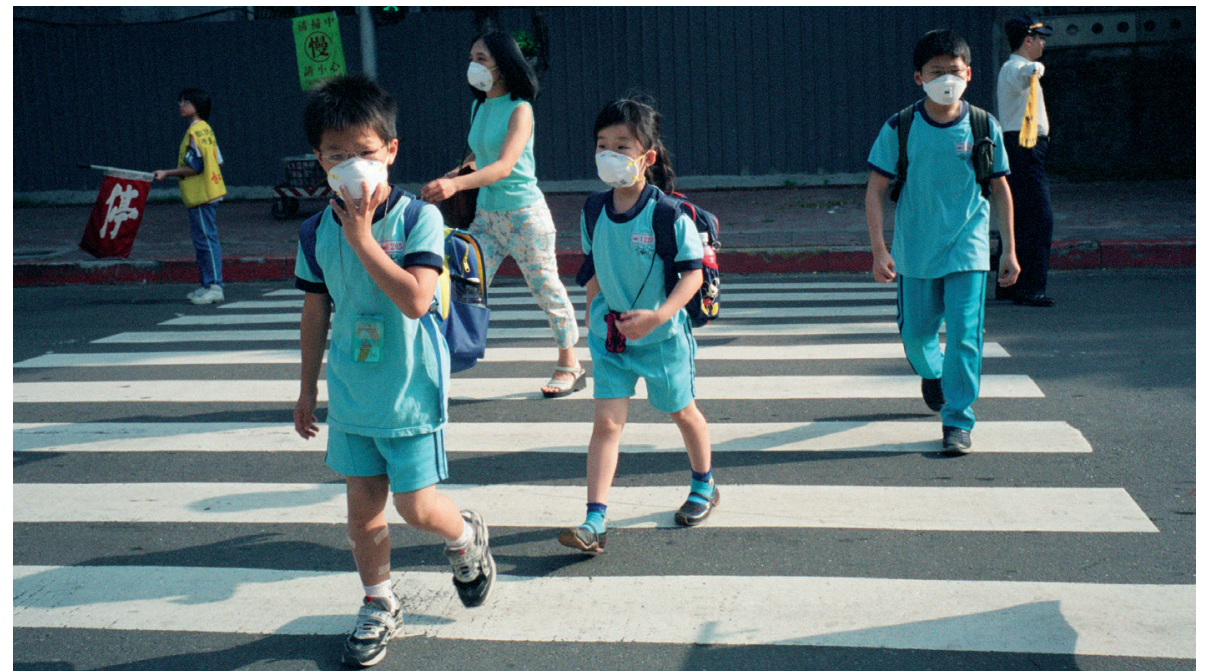

Children in Taiwan wear masks to help limit the spread of SARS.

\section{DAVID WANG SARS specialist}

\section{Pathologist at Washington University School of Medicine in St. Louis, Missouri.}

"I had been working for about two and a half years on this DNA viral microarray," a lab-ona-chip used to identify types of viruses, says pathologist David Wang. "It was a research project - we decided it would be useful in all sorts of settings. You can't decide to have a viral outbreak in the middle of your work, right?"

The viral outbreak that Wang is referring to is severe acute respiratory syndrome, known as SARS. In 2003, SARS was a mystery disease spreading across East Asia including mainland China, Taiwan, Hong Kong and Vietnam. Eventually, the disease killed 774 and hospitalized many more globally.

SARS first appeared in the south of China in November 2002, before spreading across much of the country, and infecting people as far away as Canada, Spain and Russia, aided by the flow of people through Hong Kong international airport.

SARS travels through droplets in the air, and its symptoms resemble those of flu - it often begins with a high fever. If left untreated, people can develop pneumonia, as the body responds to damage to the lungs. Because respiratory diseases can have many causes, SARS presented a challenge for the WHO - there was no way of telling if that coughing fit, perhaps in the centre of an international airport, might spread a common cold or a deadly mystery disease.

Wang, then a PhD student, had just published details of a new type of DNA microarray with his principal investigator at the time, Joseph DeRisi, now at the University of California, San Francisco. The microarray could identify a family of viruses, and so could single out SARS in a line-up of potential virus families in a way that other arrays couldn't. "People started saying, 'Wouldn't it be cool if you could get some samples to run on your array," he says. Eventually, the US Centers for Disease Control and Prevention, which were part of an international consortium investigating the disease, sent genetic samples of SARS to Wang and DeRisi.

The samples arrived at DeRisi's lab on a Saturday morning in late March 2003. By 7 p.m. on Sunday, Wang and DeRisi had characterized SARS as a coronavirus - a discovery that enabled the WHO to identify individuals who were infected with SARS, rather than another respiratory disease, and to quickly quarantine them. That quarantine was eventually what prevented the disease from spreading around the world.

"It was super exciting," Wang says. "This idea that what we were doing could make a difference today, in the short term."

"We do basic science," he adds. "The idea is that it'll be useful 5, 10, 20 years down the road when other people use it to make vaccines or build drugs."

"It's very rare," he says, "that we have the opportunity to do something that will have implications like this in the short term." Today, the response to SARS is generally considered one of the most effective global responses to a disease ever. Wang advises scientists who are in a similar situation to try to relax and avoid overthinking a protocol or analysis. "I've done this experiment a million times," he says, "I'm going to do it again."

Wang's career has continued in the field of microarrays, and he now runs a lab at Washington University in St. Louis. For his career, the timing worked out. "We were just happy to be in the right place at the right time," he says, "with a tool that was ready for prime time”.

Jack Leeming is associate Careers editor for Nature. 